\title{
Study of Substitution Mechanism in the Superconductor $\mathrm{La}_{2} \mathrm{CuO}_{4}$
}

\author{
Bassam M. Mustafa \\ Department of Physics \\ College of Science \\ Mosul University
}

(Received 21/9/2008;Accepted 16/3/2009)

\begin{abstract}
The aim of the research is to understand the mechanism of process of substitution of the ion $\mathrm{Sr}^{+2}$ instead of $\mathrm{La}^{+3}$ in the superconductor $\mathrm{La}_{2} \mathrm{CuO}_{4}$. Calculations of electrostatic potential( E. P.) for two probable positions is done to determine the site of minimum energy, the site of $\mathrm{La}$ around $\mathrm{Cu}$ ion is the minimum in energy on all the range of concentrations of the $\mathrm{Sr}$ ion. The changes in E. P. by substitution helps in understanding some aspects of the complex synthesis procedure of $\mathrm{La}_{2} \mathrm{CuO}$ compound and especially the high and the long period preparation temperature which gives full action of electrostatic forces.
\end{abstract}

Key words : ionic substitution, superconductor $\mathrm{La}_{2} \mathrm{CuO}_{4}, \mathrm{HTSC}$.

\section{درلسة آلية الستبدل الأيوفي الموطل الفلئق}

\section{المالخص}

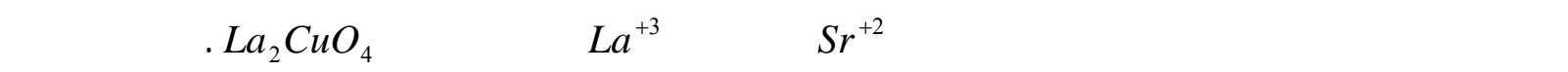

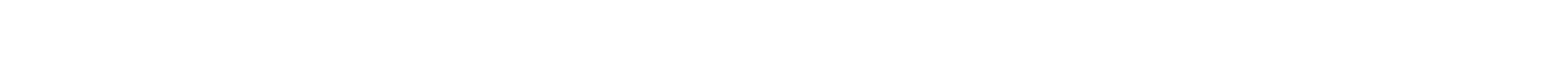

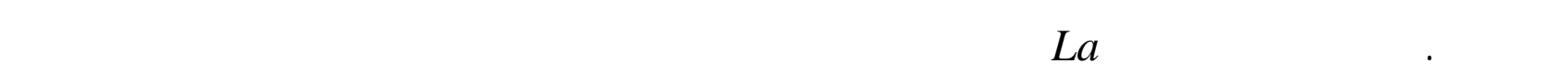

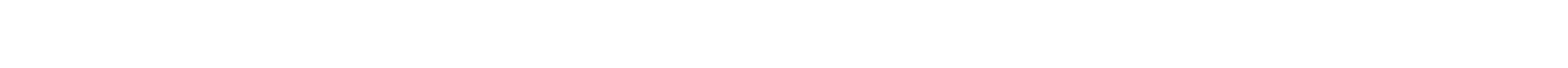
الأسلوب المعد لتصنبع المركب الطويلة للتعرض لذك.

\section{INTRODUCTION}

High Temperature Superconductors ( HTSC ) was discovered by (Bednorz and Muller, 1986), since that time great experimental efforts. Especially when the transition temperature reaches $95 \mathrm{~K}$ which is above the boiling point of liquid nitrogen (Wu et al, 1987) in the superconductor $\mathrm{YBa}_{2} \mathrm{Cu}_{3} \mathrm{O}_{7}(\mathrm{YBCO})$. The $\mathrm{HTSC}$ are $\mathrm{CuO}$ based ceramics that 
reveal superconductivity near and above $100 \mathrm{~K}$. Soon after this discovery many other superconducting compounds with higher critical temperature was synthesized, by great experimental efforts on substituting other rare earth and other near ions. Representative of such high temperature superconducting compounds are $\mathrm{Bi}-\mathrm{Sr}-\mathrm{Ca}-\mathrm{Cu}-\mathrm{O}$ (BSCCO), and $\mathrm{Ba}-$ Sr-Ca-Cu-O (BSCCO) ( Sharp, 1990). Since the discovery of the compound Hg-Ba-Ca$\mathrm{Cu}-\mathrm{O}$ (HBCCO) with the critical temperature $135 \mathrm{~K}$ there is no such great advances in elevating the critical temperature ( $\mathrm{Chu}, 2002$ ).

Basic unit of the formation of the HTSC are the Pervoskite structure which is an insulator. By substituting for certain atoms in the unit cell, it become superconductors. A tremendous quantity of substitution have been tried to improve mechanical, magnetic and transport properties of these materials (Lynn, 1990).

Superconductivity observed in $\mathrm{La}_{2} \mathrm{CuO}_{4}$ system which is shown Figure 1. When $\mathrm{La}$ is partially substituted by $\mathrm{Ba}$ then forming the compound $\mathrm{La}_{2-\mathrm{x}} \mathrm{Ba}_{\mathrm{x}} \mathrm{CuO}_{4}$ the value of $\mathrm{T}_{\mathrm{C}}$ reaches maximum value when $\mathrm{x}=0.15$. Substitution by divalent ions $\mathrm{M}=\mathrm{Ba}^{2+}, \mathrm{Sr}^{2+}, \mathrm{Cu}^{2+}$ Leads to appearance of superconductivity in a group of compounds $\mathrm{La}_{2-\mathrm{x}} \mathrm{M}_{\mathrm{x}} \mathrm{CuO}_{4-\mathrm{y}}$ for $(0.05<\mathrm{x}<0.3)$ by the variations in $x$ and $M$ ( Takagi et al , 1989) .

The aim of this research is to study the of substitution mechanism of $\mathrm{Sr}^{2+}$ ion instead $\mathrm{La}^{3+}$ in the compound $\mathrm{La}_{2} \mathrm{CuO}_{4}$ by Calculation of $\mathrm{E}$. P. to find the sit of minimum energy change for the $\mathrm{Sr}$ Ion in all range of concentration of $\mathrm{Sr}^{2+}$.
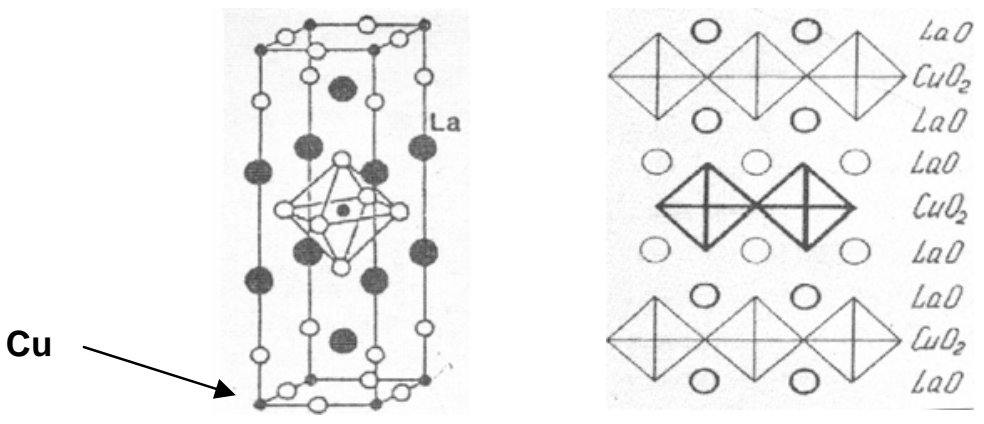

Fig.1: Left drawing the crystal structure of $\mathrm{La}_{2} \mathrm{CuO}_{4}$, on which shown the octahedral structure surrounding the $\mathrm{Cu}$ ion, right drawing is a two dimensional representation of the same compound (Illushin and Zoobov, 1991 )

\section{Theory}

The structure of the Superconducting phase was identified as a derivative of the layered pervoskite and shown in figures 1and 2. Fig.2 shows $\mathrm{CuO}_{2}$ Octahedral which consist of central $\mathrm{Cu}$ ion an $6 \mathrm{O}$ ions, with $\mathrm{Cu}-\mathrm{O}$ length of $1.9 \AA$ in the $\mathrm{a}-\mathrm{b}$ plane and $2.4 \AA$ in $\mathrm{c}$ direction. Also the $\mathrm{Cu}$ atom occur at $(000)$ and $(1 / 2,1 / 2,1 / 2)$ lattice sites in the unit cell, similar to the body centered structure. The difference in valance by substitution bring about increase in the number of holes (Sharp, 1990). Superconductors with hole conduction are called P-type similar to that found in semiconductors . 
Since $\mathrm{La}^{3+}, \mathrm{Sr}^{2+}$ are large ions the compound formed have the formula $\mathrm{A}_{2} \mathrm{BO}_{4}$, a tetragonal structure with $\mathrm{c}=3 \mathrm{a}$. Where $\mathrm{a}$ is the length of the cell edge of the pervoskite building bricks (Sharp, 1990).

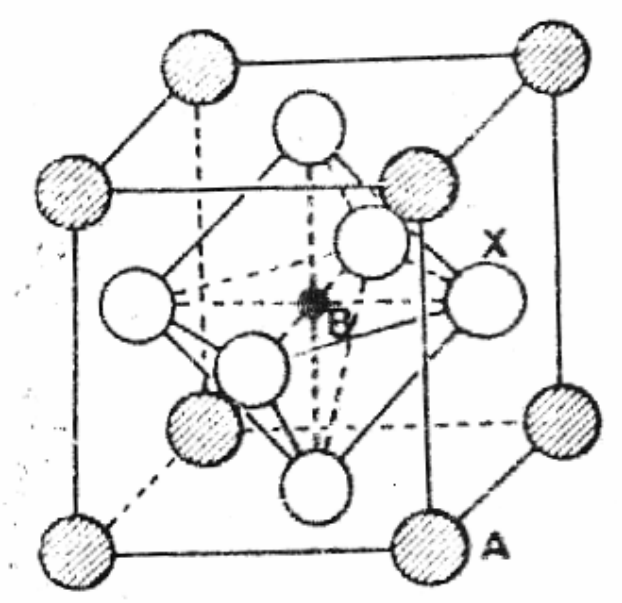

Fig.2: Central cube in the $\mathrm{La}_{2} \mathrm{CuO}_{4}$ crystal, with pervoskite structure, where $\mathrm{A}, \mathrm{B}$ and $\mathrm{x}$ representing ( $\mathrm{La}$ or $\mathrm{Sr}$ ), $\mathrm{Cu}$ and $\mathrm{O}$ respectively (Santoro, 1990).

The $\mathrm{CuO}$ compounds are insulators (Sharp, 1990) by substituting a certain atoms in the unit cell, these materials are made to behave as metals and may become superconductors (Wright and Butler, 1990). The process of substitution was done experimentally, little is done to understand theoretically what happens during substitution. one of the reasons as we think is the good gained results of ever higher temperature superconductor, but soon this good results was stopped, and more than one decade was elapsed and record transition temperature is not changed. Here we try to read the main features for a better theoretical understanding of the experimental procedure.

Great number of studies (Santoro, 1990) by X-ray, electron and neutron diffraction of HTSC during substitution by different percentages of substituent's show after a thermal treatments in certain atmospheres that these substituent's are taken certain positions in the crystal unit cell with the substituted ions also distributed approximately in a uniform manner in the whole superconducting specimen (Shelton ,1990).

For the compound $\mathrm{La}_{2} \mathrm{CuO}_{4}$ as shown in figures 1 and 3 , there are two positions for the $\mathrm{Sr}$ atom to be substituted one position is that the substituted atom takes the position of one of the eight $\mathrm{La}$ atoms around the $\mathrm{Cu}-\mathrm{O}$ octahedral and the position is denoted as $\mathrm{La}(1)$, the other probable position is in one of the positions of the other La two atoms above and below the $\mathrm{Cu}-\mathrm{O}$ octahedral as seen also in figure 3 where position is denoted as $\mathrm{La}(2)$. 


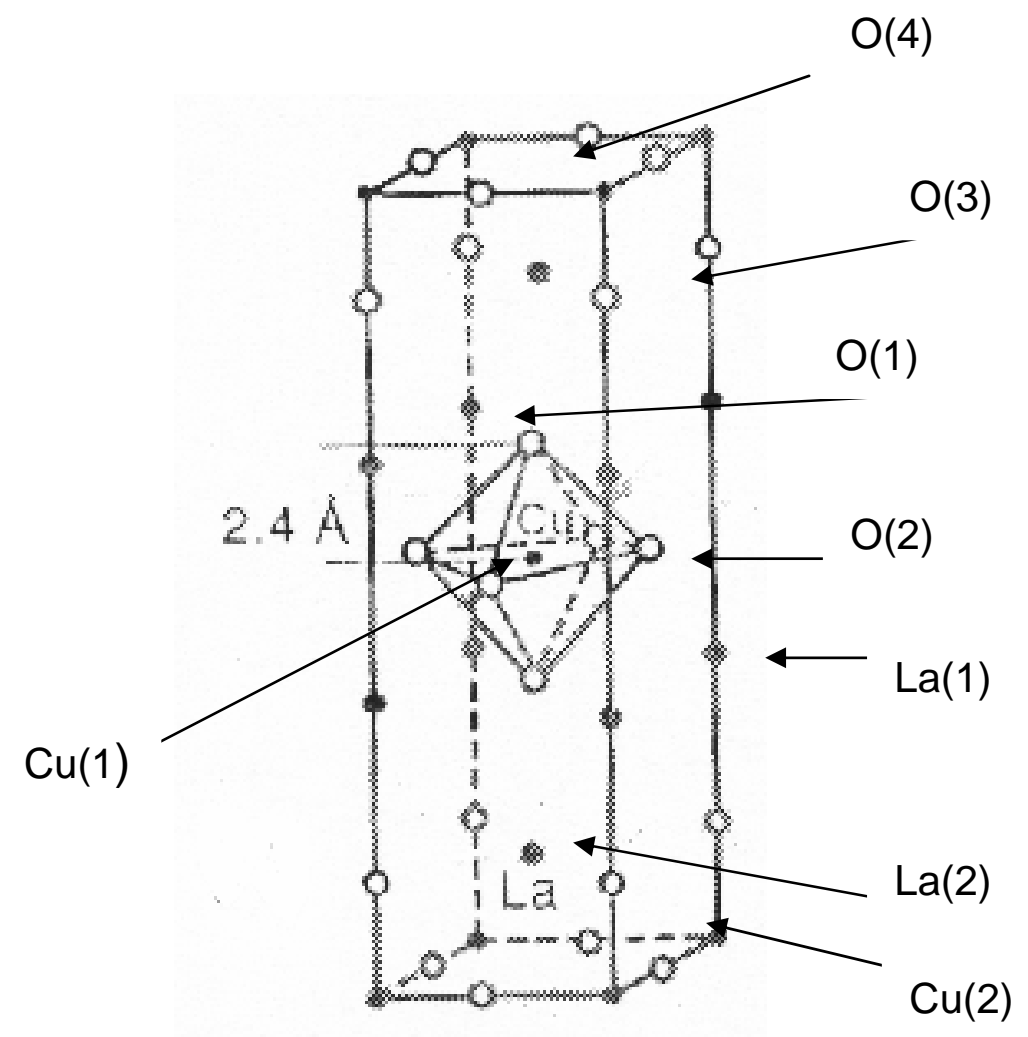

Fig. 3: Crystal structure of the compound $\mathrm{La}_{2} \mathrm{CuO}_{4}$, here nomination the sites of the atoms is done to understand the process of substitution (Sharp, 1990) the arrows on the figure and their nominations is drawn by the author.

Many researches concluded that the substituted atom takes the position $\mathrm{La}(1)$ but there is no proof for such assumption. Here we try to analyze this contradiction and to do this the following facts must be considered :

1 - The HTSC are ionic compounds (Wright and Butler, 1990) .

2 - Accordingly electrostatic forces play a major role in formation of the compound .

3 - The valance of the substituted ions.

4 - The difference in energy between the two position of settlements of the substituted ion.

5 - The size of the original and the substituted ion.

6 - Atom will prefer the position of the least change in the energy of the crystal. Therefore a need to calculate the electrostatic energy is necessary which includes many of the factors which we have already stated.

\section{The size of the substituted ion}

Size of the substituted ion plays a role in determining the position of the substituted ion, since there is a difference in radii of the ions this accordingly affect the E. P, especially if their is a big difference in radii of the ions. But here the substituted ion $\operatorname{Sr}(1.13 \AA$ ) has approximately the same radius as that of $\mathrm{La}(1.15 \AA$ ) the difference is very small and in 
calculating the E. P. very little difference appear when putting the size factor under consideration .

\section{The electrostatic energy}

Great number of literature concluded that one of the important properties of the HTSC are their ionic bonds (Wright and Butler, 1990). This is one of the main properties of the pervoskite structures. Since all the HTSC are derived from materials with pervoskite structures (Sharp, 1990).

If we try to compute the electrostatic energy (E.P.), which as we think: is an important parameter, because it determine to a big extent the energy that combine the system of atoms in the crystal, and any change in it (substitution of a new atom) affect the combining energy of the whole system this will affects also charge distribution inside the crystal, because it affect the charge balance by the introduction of the new ion, with different valances .

To calculate the electrostatic energy $\mathrm{E}$ for the crystal we use the following relation (Kittle, 2005 ).

$$
E=\frac{1}{4 \pi \varepsilon_{o}} \sum_{1}^{i} \frac{Q q_{i}}{r}
$$

$Q, q_{i}, r \quad$ are the charge of the reference ion, the charge of the ion $i$ and the distance between them respectively. Madelung method (Kittel, 2005) was not followed strictly because of the anisotropy and the distortion of this crystal as shown in the figures 1,2 and 3 . So we have to modify (equation 1) to account for the three type of ions present in the crystal (i.e. $\mathrm{Cu}, \mathrm{O}, \mathrm{Ba}$ ), thus

Calculation of EE for the crystal depend on the site of the reference atom,

$$
E=\frac{1}{4 \pi \varepsilon_{o}}\left(\sum_{1}^{m} \frac{Q q_{C u}}{r_{Y-C u}}+\sum_{1}^{n} \frac{Q q_{O}}{r_{Y-O}}+\sum_{1}^{l} \frac{Q_{B a}}{r_{Y-B a}}\right)
$$

and the distance of the other atoms relative to it .therefore we need to identify the positions and distances of the atom in the crystal .

\section{positions and distances of the atom in the crystal}

For our crystal $\mathrm{La}_{2} \mathrm{CuO}_{4}$, and as shown in figures 1 and 2. The crystal have tetragonal structure as shown in figure 3. with $\mathrm{c}=3 \mathrm{a}$ (Sharp, 1990). Where a is the length of the cell edge of the pervoskite building bricks.

The $\mathrm{c}$ and a dimensions as measured by X-ray and neutron diffraction and for the compound $\mathrm{La}_{2} \mathrm{CuO}_{4}$ are (Santoro, 1990) :

$$
\mathrm{c}=13.288 \AA
$$

In figure 3 the crystal structure for $\mathrm{La}_{2} \mathrm{CuO}_{4}$ is shown and the main atomic sites for this crystal is nominated. In the table 3 positions for the above atoms are tabulated, for the equal atomic sites like $(\mathrm{La}(1), \mathrm{O}(2)$..etc) we refer to site near the reference point 
Table 1: Atomic positions of the main atomic sites in the crystal of the superconductor $\mathrm{La}_{2} \mathrm{CuO}_{4}$

\begin{tabular}{|c|c|c|c|l|}
\hline Atomic site & $\mathbf{x}$ & $\mathbf{Y}$ & $\mathbf{Z}$ & Reference \\
\hline $\mathrm{Cu}(1)$ & $0.5 \mathrm{a}$ & $0.5 \mathrm{a}$ & $0.5 \mathrm{c}$ & Santoro, 1990 \\
\hline $\mathrm{Cu}(2)$ & 0 & 0 & 0 & Santoro, 1990 \\
\hline $\mathrm{La}(1)$ & 0 & 0 & $0.362 \mathrm{c}$ & Santoro, 1990 \\
\hline $\mathrm{La}(2)$ & $0.5 \mathrm{a}$ & $0.5 \mathrm{a}$ & $0.138 \mathrm{c}$ & Picket, 1989 \\
\hline $\mathrm{O}(1)$ & $0.5 \mathrm{a}$ & $0.5 \mathrm{a}$ & $0.681 \mathrm{c}$ & Sharp, 1990 \\
\hline $\mathrm{O}(2)$ & $0.5 \mathrm{a}$ & 0 & $0.5 \mathrm{c}$ & Sharp, 1990 \\
\hline $\mathrm{O}(3)$ & 0 & 0 & $0.182 \mathrm{c}$ & Picket, 1989 \\
\hline $\mathrm{O}(4)$ & 0.5 & 0 & 0 & Santoro, 1990 \\
\hline
\end{tabular}

We have two probable situations where the $\mathrm{Sr}$ ion can be settled the first situation is the site of one from the eight $\mathrm{La}$ (1) ions surrounding the $\mathrm{Cu}$ (1) ion. The other probable site is the site of one of the two La (2) ion in the upper and lower parts of the crystal. In order to determine the most probable situation the following must be considered. The site that Sr Ion will choose must not lead to breaking the crystal, and as a result changing its nature, but we want this substitution to improve superconducting properties of the crystal unit cell. This condition lead us to go to the fact that the system is still stable if the change of its total energy is minimum by the substitution depend. So the site of stability of the $\mathrm{Sr}$ ion is the one that will produce minimum energy change in crystal energy.

So since the HTSC compounds are ionic compounds as its already mentioned above we must calculate the change in the electrostatic potential (E.P.) due to the substitution.

\section{Calculation of Electrostatic potential in $\mathrm{Cu}(1)$ site}

In this site the $\mathrm{Cu}$ ion is surrounded by two $\mathrm{O}(1)$, and four $\mathrm{O}(2)$ ions and eight $\mathrm{La}$ (1) ions so :

The E.P. between $\mathrm{Cu}(1)$ and $\mathrm{O}(1)$ ions

$$
E_{r_{C u(1)-O(1)}}=\frac{1}{4 \pi \varepsilon_{o}}\left(\sum_{1}^{2} \frac{Q_{O(1)} q_{C u(1)}}{r_{C u(1)-O(1)}}\right)
$$

and The E.P. between $\mathrm{Cu}(1)$ and $\mathrm{O}(2)$ ions

$$
E_{r_{C u(1)-O(2)}}=\frac{1}{4 \pi \varepsilon_{o}} \sum_{1}^{4} \frac{Q_{(2)} q_{C u(1)}}{r_{C u(1)-O(2)}}
$$

and The E.P. between $\mathrm{Cu}(1)$ and $\mathrm{La}(1)$ ions 


$$
\left.E_{C u(1)-L a(1)}=\frac{1}{4 \pi \varepsilon_{o}} \sum_{1}^{8} \frac{Q_{L a(1)} q_{C u(1)}}{r_{C u(1)-L a(1)}}\right)
$$

thus the total P. E. in the site $\mathrm{Cu}(1)$ before substitution of the ion $\mathrm{Sr}$ is :

$$
E_{T C u(1)}=E_{r_{C u(1)-O(1)}}+E_{r_{C u(1)-O(2)}}+E_{C u(1)-L a(1)}
$$

and the total P. E. in the site $\mathrm{Cu}(1)$ after substitution of the ion $\mathrm{Sr}$ is :

$$
E_{T C u(1)}=\left(E_{r_{C u(1)-O(1)}}+E_{r_{C u(1)-O(2)}}+E_{C u(1)-L a(1)}\right)(1-x)-x E_{C u(1)-S r(1)}
$$

where $\mathrm{x}$ is the concentration of Srions

\section{Calculation of Electrostatic potential in La(2)site}

In this site the $\mathrm{La}(2)$ ion is surrounded by one $\mathrm{O}(1)$, and four $\mathrm{O}(3)$ ions and four $\mathrm{La}$ (1) ions and so :

The E.P. between $\mathrm{La}(2)$ and $\mathrm{O}(1)$ ions

$$
E_{r_{L a(2)-O(1)}}=\frac{1}{4 \pi \varepsilon_{o}}\left(\sum_{1}^{1} \frac{Q_{O(1)} q_{L a(2)}}{r_{L a(2)-O(1)}}\right)
$$

The E.P. between $\mathrm{La}(2)$ and $\mathrm{La}(1)$ ions

$$
E_{r_{L a(1)-L a(2)}}=\frac{1}{4 \pi \varepsilon_{o}} \sum_{1}^{3} \frac{Q l_{L a(2)} q_{L a(1)}}{r_{L a(1)-L a(2)}}
$$

The E.P. between $\mathrm{La}(2)$ and $\mathrm{O}(3)$ ions

$$
\left.E_{r_{L a(1)-O(3)}}=\frac{1}{4 \pi \varepsilon_{o}} \sum_{1}^{4} \frac{Q_{L a(1)} q_{O(3)}}{r_{L a(1)-O(3)}}\right)
$$

The E.P. between la(2) and $\mathrm{O}(4)$ ions

$$
E_{r_{L a(1)-O(4)}}=\frac{1}{4 \pi \varepsilon_{o}}\left(\sum_{1}^{4} \frac{Q_{L a(1)} q_{O(4)}}{r_{L a(1)-O(4)}}\right)
$$

The E.P. between $1 \mathrm{la}(2)$ and $\operatorname{Sr}(1)$ ions

$$
\left.E_{r_{L a(2)-S r(1)}}=\frac{1}{4 \pi \varepsilon_{o}} \sum_{1}^{1} \frac{Q_{S r(1)} q_{L a(2)}}{r_{L a(2)-S r(1)}}\right)
$$

thus the total P. E. in the site $\mathrm{La}(2)$ before substitution of the ion $\mathrm{Sr}$ is :

$$
E_{T L a(2)}=E_{r_{L a(2)-O(1)}}+E_{r_{L a(1)-L a(2)}}+E_{r_{L a(1)-O(3)}}+E_{r_{L a(1)-O(4)}}+E_{r_{L a(1)-C u(2)}}
$$

and the total P. E. in the site $\mathrm{La}(2)$ after substitution of the ion $\mathrm{Sr}$ is :

$$
E_{T L a(2)}=\left(E_{r_{L a(2)-O(1)}}+E_{r_{L a(1)-L a(2)}}+E_{r_{L a(1)-O(3)}}+E_{r_{L a(1)-O(4)}}+E_{r_{L a(1)-C u(2)}}\right)(1-x)-x E_{r_{L a(2)-S r(1)}}
$$

where $\mathrm{x}$ is the concentration of Srions. 


\section{Calculations, Results and Discussion}

The other parameters which are needed to calculate EE is distances between the atoms and the reference atom.

$\mathrm{r}_{\mathrm{Cu}-\mathrm{O}(1)}=2.4 \AA \AA$, ( Sharp) distance for apex $\mathrm{O}$ atom from central $\mathrm{Cu}$ atom .

$\mathrm{r}_{\mathrm{Cu}-\mathrm{O}(1)}=1.9 \AA$ ( Sharp) distance for $\mathrm{O}$ atom in $\mathrm{CuO}$ plane from central $\mathrm{Cu}$ atom .

From the positions of the ions in table 1 , and using the above dimensions we can find :

$\mathrm{r}_{\mathrm{La}(1)-\operatorname{La}(1)}=\frac{13.288-3.620 \times 2}{13.288} c=0.455 c$

the length of half diagonal is $\mathrm{D}_{1 / 2}=\frac{a}{2} \sqrt{2}=2.678 \AA$

Substituting for a and $\mathrm{c}$ then $\mathrm{r}_{\mathrm{Cu}-\mathrm{La}(1)}=3.570 \AA$

Mid point of the crystal $=\mathrm{c} / 2=6.644 \AA$

$$
\begin{aligned}
& \mathrm{c}_{\mathrm{O}(1)}=9.044 \AA \\
& \mathrm{c}_{\mathrm{La}(2)}=10.803 \AA \\
& \mathrm{c}_{\mathrm{La}(1)}=8.478 \AA \\
& \mathrm{c}_{\mathrm{O}(3)}=11.468 \AA \\
& \mathrm{r}_{\mathrm{La}(2)-\mathrm{O}(1)}=1.759 \AA \\
& \mathrm{r}_{\mathrm{La}(2)-\mathrm{La}(1)}=2.325 \AA \\
& \mathrm{r}_{\mathrm{La}(2)-\mathrm{O}(3)}=2.759 \AA \\
& \mathrm{r}_{\mathrm{La}(2)-\mathrm{O}(3)}=2.759 \AA \\
& \mathrm{r}_{\mathrm{La}(2)-\mathrm{Cu}(2)}=3.653 \AA \\
& \mathrm{r}_{\mathrm{La}(2)-\mathrm{O}(4)}=3.124 \AA
\end{aligned}
$$

Valance of the ions are $\mathrm{La}=+3, \mathrm{Cu}=+3, \mathrm{Sr}=+2, \mathrm{O}=-2$ (Sharp, 1990) using the above values for the distances from the reference atom in the sites $\mathrm{Cu}(1)$, and by substituting in equations 7 we see the change in the electrostatic potential by substitution of Sr instead of one of the $\mathrm{La}(1)$ ions as in figure 4.

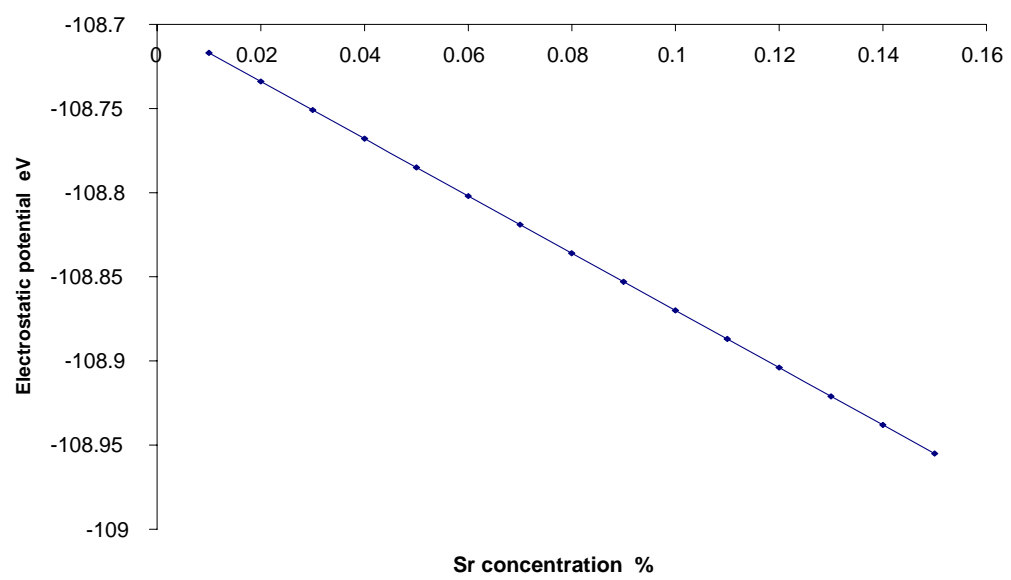

Fig. 4: Change in the electrostatic potential by substitution of $\mathrm{Sr}$ instead of one of the $\mathrm{La}(1)$ ions. 
Using the above values for the distances from the reference atom in the sites $\mathrm{La}(2)$, and by substituting in equations 14 we see the change in the electrostatic potential by substitution of $\mathrm{Sr}$ instead of one of the $\mathrm{La}(2)$ ions as in figure 5 .

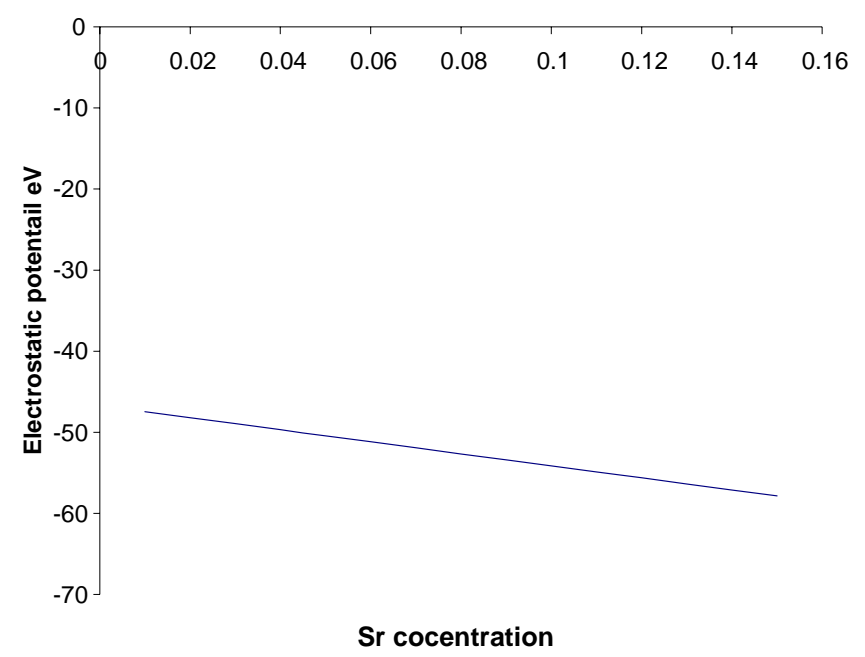

Fig. 5 : Change in the electrostatic potential by substitution of Sr instead $\mathrm{La}(2)$ ion .

By comparing the change in the P. E. by the substitution of the ion $\mathrm{Sr}$ in the sites $\mathrm{Cu}(1)$ and $\mathrm{La}(2)$ we find a great difference in the values of P.E. between the two sites, this is very evident in figure 6 where the P.E. is drawn as a function of $\mathrm{Sr}$ concentration for the two sites

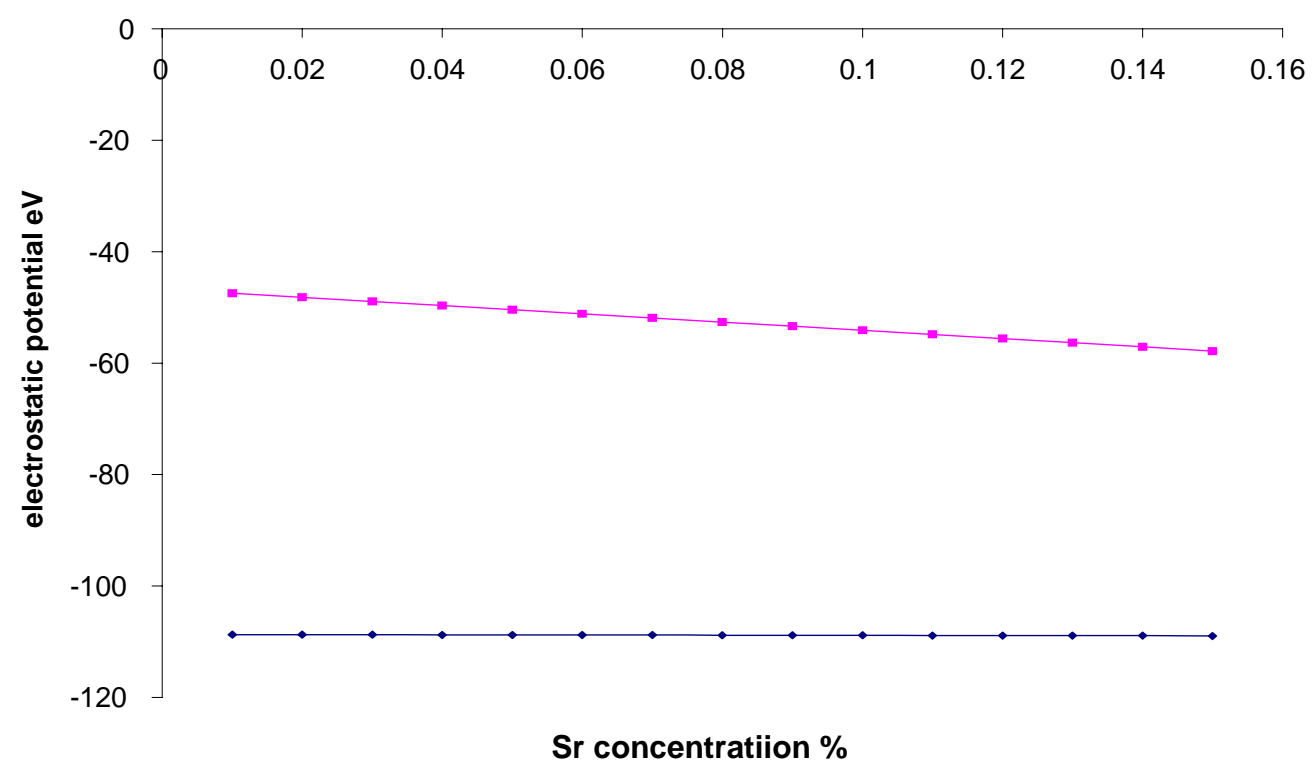

Fig. 6: Comparison of the drawing of P.E . as a function of $\mathrm{Sr}$ concentration for the sites $\mathrm{La}(2)$ (upper curve ) and $\mathrm{La}(1)$ (lower curve) . 
As shown from figure 6 substitution of $\mathrm{Sr}$ in the site $\mathrm{La}(2)$ lead to a greater change in (P. E.) than the substitution in the site $\mathrm{Cu}(1)$. This give indication that substitution instead of $\mathrm{La}(1)$ ion bring very small change in the P.E. so such substitution is the most probable Thus we have given the proof for settlement of $\mathrm{Sr}$ ion in the site. Our above result can explain the work of (Shelton, 1990) about the uniform distribution of the substituted atoms in the superconducting specimen, this happens because atoms takes certain sites in the crystal structure according to the ( P. E.) for the crystal structure of that compound. This potential energy is the same for all crystals of the specimen so uniform substitution atoms occur.

As an ionic compound and as have been proved in this research that electrostatic potential play a major role in determining the site that the substituted atom will settled. This lead to think about the complex synthesis procedure (which will give a brief bellow ) for the HTSC and one of them is the compound under study it is clear that electrostatic potential supply the stabilization of the superconducting compounds.

Complete synthesis procedure involve a sequence with individual steps. The starting materials are $\mathrm{Cu}$ and La oxides. The constituents powders must be mixed thoroughly the powders absorbed moister from air. This moister can be driven out by heat treatment. The mixed powder are pressed into pellet and in suitable crucible is subjected to a series of heat treatments to produce the solid state reaction that forms the $\mathrm{K}_{2} \mathrm{NiF}_{4}$-type phase at temperature about $1000 \mathrm{C}$ for 24 to $48 \mathrm{~h}$, then if X-ray shows existence of secondary phase then heat treatment repeated, then another heat treatment at a lower temperature in Oxygen atmosphere then done, then slow cooling at a very slow rate is done .

The first step of synthesis is mixing the oxides that forming the crystals approximately uniformly such that it is ready to the solid state reaction i.e. in any small volume of about volume of the crystal all constituents are exist. But in order that the above constituents will form the superconducting compounds, dissociation of this oxides must occur, and constituents must go into total or partial ionization, this lead to the action of the electrostatic forces to act between the ions and then forming the compound. In order that such dissociation of this oxides to occur, and constituents go into total or partial ionization high preparation temperature about $1100 \mathrm{~K}$ and its long duration, this long period give the sufficient time for the electrostatic forces to play its role so the that the compound is formed.

\section{CONCLUSION}

1 - Calculation of the electrostatic potential shows that change in the crystal energy is minimum if $\mathrm{Sr}$ is settled in one of the sites of the La ions around the central octahedral in the superconducting compound $\mathrm{La}_{2} \mathrm{CuO}_{4}$ in comparison with the sites of $\mathrm{La}$ ions above and below the central octahedral.

2 - Electrostatic potential of the crystal explains mechanism of substitution of $\mathrm{Sr}$ in the superconducting compound $\mathrm{La}_{2} \mathrm{CuO}_{4}$ this explains also some of the aspects of the complex procedure of synthesis of HTSC . 


\section{REFERENCES}

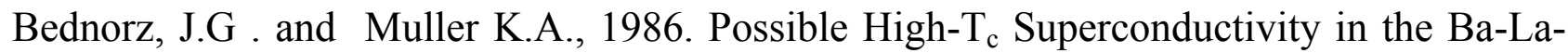
Cu-O System , Z. Phys. B. ,V.64, pp.186- 193.

Chu , C.W. , 2002. Materials and Physics of High Temperature Superconductors, Hong Kong University Press, 411p.

Illushin, A.S. and Zoobov E .V., 1991. Introduction to Physical Structural Analysis of HTSC, Moscow University Printing Press, Moscow, in Russian Language, $112 \mathrm{p}$.

Khosroabadi , H. H.; Zadeh M.R. Mohammadi and Akhavan M., 2002. Structural and Electronic Properties of $\mathrm{YBa}_{2} \mathrm{Cu}_{3} \mathrm{O}_{7}$ Under High Pressure, Physica C 370: 85 p.

Kittel, C., 2005. Introduction to Solid State Physics. 8th Edn., John Wiley and Sons, $883 p$.

Lynn, J. W., 1990. Survey of Superconductivity, in High Temperature Superconductivity, Edited by Lynn, J. W., Springer - Verlag, New York, 390 p.

Pickett, W. E., 1990. Electronic Structure of the High-Temperature Oxide Superconductors, Rev. Mod., Phys. Vol.61, No.2. pp.433 -512.

Santoro, A ,1990. Crystallography, in High Temperature Superconductivity, Edited by Lynn , J. W., Springer - Verlag, New York, 390p.

Sharp, J.H. , 1990. Structural Chemistry of Mixed Oxides Superconductors, Br. Ceram. Trans., J.,V. 89, No. 1, pp.1-7.

Shelton , R., N., 1990. Synthesis and Diamagnetic Properties, in High Temperature Superconductivity, Edited by Lynn, J. W., Springer - Verlag, New York, 390p..

Takagi , H.T.; Ishibashi Ido S.; Uota M. and Uchida S., 1989. Slow Spin Glass and Fast Spin Liquid Component in Quasi- two Dimensional La, Phys. Rev. B .,Vol. 40 : 2254 p. .

Wright, N.F and Butler W.H., 1990. Ionic Model for the Stability of the Y-Ba-Cu HighTemperature Superconductors, Phys. Rev., Vol.42, No.7, 4219 p.

Wu, M. K.; Ashburn, J. R. and Torn C. J. , 1987. Superconductivity at 93 K in a New Mixed Phase Y-Ba-Cu-O Compound System at Ambient Pressure, Phys. Rev. Lett., V. 58, No. 9, pp.908-910 . 